\title{
Risk Management Research of Financial Market based on Dynamic Copula Model
}

\author{
CHAI Yixian ${ }^{1}$, XU Yanli ${ }^{2,3}$ and LIU Dan ${ }^{4, a}$ \\ ${ }^{1}$ Management Department for State-owned Assets, Harbin Normal University, P. R. China, 150025 \\ ${ }^{2}$ School of Economics and Management, Guangdong University of Petrochemical Technology, \\ Maoming Guangdong, P. R. China, 525000 \\ ${ }^{3}$ Harbin Normal University, Harbin, P. R. China, 150025 \\ ${ }^{4}$ Library, Guangdong University of Petrochemical Technology, Maoming, P. R. China, 525000 \\ ${ }^{a}$ Corresponding author: liudan100liudan@163.com
}

Keywords: dynamic Copula model, financial market risk management, contagion effect

\begin{abstract}
Copula model and the application of the model in financial market risk management are discussed in this paper. The paper establishes a dynamic Copula model to solve the financial market risk management problems on the basis of Copula research. Through the use of statistics and financial theories and Copula model, the thesis studies the applications of Copula model in the financial risk management and resolves the problem whether there exists financial crisis contagion or not. The results indicate that the applications of model in the financial market risk management are effective, and the research on the problem should be done in-depth.
\end{abstract}

\section{Introduction}

Recently the function of Copula has been more and more appreciated in the field of statistical modeling and applying research of financial market and so on. It not only adapted the need of modern financial market and practice development, but it is also tightly tied to the development of modern financial statistics and financial econometric theory. According to the modern financial theory, the core problem of financial is that the intertemporal optimal allocation of the resources in the indefinite environment, how to make time and uncertainty become the most factor influencing financial market. And the uncertainty is the source of financial risk.

At the background above, quantitative risk management technology based on the method of mathematical statistics and modern financial theory developed and applied widely and deeply. But the study of quantitative risk management technology mainly focused on the aspect of unary statistical modeling. Multi statistical modeling is usually on the base of multivariate normal distribution or multiple $t$ distribution. But practice usually indicates that this kind of hypothesis not precisely conforms to actual statistical features of financial data. And the kind of model maybe exist major risk of model setup. So we need more flexible and precise methods and means to depict statistical feature of multivariate financial assets distribution. As a quantifying risk management technology of depicting statistical feature of multivariate variable distribution, Copula function has become more and more important in the field of financial risk management recently.

\section{The Construction of Dynamic Copula Model}

Because the key to build dynamic correlation Copula model is to get the evaluating equation of correlation. The earliest scholar who studied the dynamic correlation Copula model was Patton. He put forward that correlation can be explained by correlation before and the history average value of two values accumulating probability according to Hansen's spirit of conditional density model. In the passage of Patton (2006), Patton put forward conditional Copula dynamic correlation value model below according to Hansen's spirit of conditional density model: 


$$
\begin{aligned}
& \rho_{t}=\Lambda\left[\omega_{N}+\beta_{N} \rho_{t-1}+\alpha_{N} \frac{1}{10} \sum_{j=1}^{10} \Phi^{-1}\left(u_{t-j}\right) \Phi^{-1}\left(v_{t-j}\right)\right] \\
& \rho_{t}=\Lambda\left[\omega_{r}+\beta_{r} \rho_{t-1}+\alpha_{r} \frac{1}{10} \sum_{j=1}^{10} T^{-1}\left(u_{t-j} ; v\right) T^{-1}\left(v_{t-j} ; v\right)\right]
\end{aligned}
$$

$\Phi^{-1}$ is inverse function of accumulated distribution functions of $\operatorname{PROBNORM} . T^{-1}(; v)$ is inverse function of accumulated distribution functions of $\mathrm{t}, \Lambda=\left(1-e^{-x}\right) /\left(1+e^{-x}\right)$ is logistic function that has been modifying. It ensures the correlation values belonging from -1 to 1 .In order to be simple; Patton supposed that the variance of $t$ distribution didn't change. On the base of Patton' work, Goorbergh, Genest and Werker(2003)put forward to study multielement option valuation with dynamic Copula model. And the evolution equation of the Copula function values can be evaluated by rank correlation value $\mathrm{f}$.

Among them, $h_{1 t}, h_{2 t}$ represent respectively asset 1,2 fluctuating at the time of $\mathrm{t} . \gamma(\cdot)$ is designated function. It depicts changes of correlation of asset under different fluctuation level. Considering the correlation among asset changing with the fluctuation of asset profit, usually, we thought great fluctuations will strength the correlation. So there is one of the forms of function $\gamma(\cdot)$.

$\mathrm{L}$ is lag operator, $\left|u_{t-1}-v_{t-1}\right|$ is absolute value of the dissimilarity of two historical variables. It is used to get the changes of dependent process. The larger the dissimilarity of accumulation of probability that has been achieved is, the higher the dependence will be.

Patton has put forward symmetrical Joe-Copula model in order to overcome faultiness of Joe-Copula function. The model is like this:

$$
C_{S J C}=0.5\left(C_{J C}\left(u, v \mid \tau^{l}, \tau^{u}\right)+C_{J C}\left(1-u, 1-v \mid \tau^{l}, \tau^{u}\right)+u+v-1\right.
$$

The evolution equation of tail correlation coefficient is

$$
\begin{aligned}
& \tau_{t}^{u}=\Lambda\left(\omega_{u}+\beta_{u} \tau_{t-1}^{u}+\alpha_{u} \frac{1}{10} \sum_{j=1}^{10}\left|u_{t-j}-v_{t-j}\right|\right) \\
& \tau_{t}^{l}=\Delta\left(\omega_{t}+\beta_{u} \tau_{t-1}^{l}+\alpha_{l} \frac{1}{10} \sum_{j=1}^{10}\left|u_{t-j}-v_{t-j}\right|\right)
\end{aligned}
$$

Among of these, $\Lambda(x)=\left(1-e^{-x}\right)^{-1}$ is logic variable. The model is similar with $\operatorname{ARMA}(1,10)$ model. The right tail correlation model include $\beta_{u} \tau_{t-1}^{u}$ and $\beta_{u} \tau_{t-1}^{l}$, a limited variable. It is difficult to choose orders. After tentative calculation, we choose $\left|u_{t-j}-v_{t-j}\right|$ of 10 orders as the limitation. After valuing the evolution equation of parameter, according to consistence and correlation or tail correlation coefficient, we can get the evolution equation of Copula. For example, in the function of JC-Copula, reforming $\tau^{t}=2^{-1 / \gamma}, \tau^{w}=2-2^{1 / k}$, we can get the equation:

$$
\left.\gamma_{t}=-\left[\log _{2}\left(\tau_{t}^{l}\right)\right]^{-1}, \kappa_{t}=\log _{2}\left(2-\tau_{t}^{u}\right)\right]^{-1}
$$

We can see that the key to build dynamic correlation Copula model is to be given the evolution equation of parameter, according to consistence and correlation or tail correlation coefficient. Deam Fantazzini(2006) ${ }^{[1]}$ made dynamic Copula model combine with VaR. He used the method of Motel Carlo to estimate invest combination VaR which is consist of SP500 index, Dax index and Nikkei225 index. It indicated that it was precise to measure the risk of invest combination with dynamic Copula.

The thesis combining the models of Deam Fantazzini(2006) and Patton(2006b),provides the model. And it expands the hypothesis of unchanging variance of t-Copula and built two evolution equations that used to estimate dynamic Copula function of bi-variants time series.

1) the parameter of normality-Copula

$$
\rho_{t}=\Lambda\left(\omega+\beta \rho_{t-1}+\alpha\left|u_{t-1}-v_{t-1}\right|\right)
$$

2) the parameter of T-Copula 


$$
\begin{aligned}
& \rho_{t}=\Lambda\left(\omega+\beta \rho_{t-1}+\alpha\left|u_{t-1}-v_{t-1}\right|\right) \\
& v_{t}=\Lambda\left(\zeta+\delta\left|u_{t-1}-v_{t-1}\right|\right)
\end{aligned}
$$

Among of them, $\omega, \beta, \alpha, \zeta, \delta$ are estimating parameters. $\Lambda(x)=\left(1-e^{-x}\right)\left(1+e^{-x}\right)$ is modified logistic function, ensuring $\rho_{t} \in(-1,1) . \Lambda(x)=2+28 /\left(1+e^{-x}\right)$ is logistic transformation, ensuring variance in $[2,30]$.

\section{The Application of Copula Model in the Field of Financial Risk Management}

The Contagion Effect in Financial Market. It is said that if two asset markets have obviously different correlation in crisis period and non-crisis period, that is the happening of crisis break the correlation among markets and make the correlation strength, we can say that the crisis markets exist crisis contagion ${ }^{[2]}$.If one country's stock market happen great fluctuation, the relationship among transnational markets strength. According to the understanding, Bertero and Mayer (1989) ${ }^{[3]}$, King and Wadhwani(1990) ${ }^{[4]}$,Calvo and Reinhardt (1996) ${ }^{[5]}$, Baij and Goldfajn(1998) ${ }^{[6]}$ and so on have studied on some big crisis of international and concluded that the happen of crisis has strength the correlation of international asset, that is there is crisis contagion. But the following studies challenge the conclusion above. Forbes and Rigobon(2002) ${ }^{[7]}$ according to Boyer,Gibson and Loretan(1999) ${ }^{[8]}$ have studied several international financial crisis. They conclude that international markets have correlation in non-crisis period. What is called crisis contagion is just the result of fluctuation increasing continually.

The Application of Copula Model in Financial Contagion Analysis. In fact, the correlation of financial market will usually change with the fluctuation of the financial market. But under different fluctuating levels, financial markets have different correlation.

We can use a simple example to illustrate the application of Copula model in crisis contagion.

Supposed that marginal distribution of financial income sequence $\left\{y_{1 t}\right\}_{t=1}^{T},\left\{y_{2 t}\right\}_{t=1}^{T}$ can be depicted by the model of MRS-CARCH(2,1,1).It has high and low status of fluctuation. We supposed that transmit of Copula function structure and transmit of the source of contagion is the same. The transmit between 1 and 2 should the process of one order Markov.But under different fluctuation systems ,the correlation structure of financial market can be depicted by mix Copula function:

$$
\begin{gathered}
M C_{3}\left(u_{t}, v_{t}\right)=w_{g}\left(s_{t}\right) C_{g}\left(u_{t}, v_{t} ; \alpha\right)+w_{c}\left(s_{t}\right) C_{e}\left(u_{t}, v_{t} ; \theta\right)+w_{f}\left(s_{t}\right) C_{f}\left(u_{t}, v_{t} ; \lambda\right) \\
w_{g}\left(s_{t}\right)=w_{1 g}+\left(w_{2 g}-w_{1 g}\right)\left(s_{t}-1\right)
\end{gathered}
$$

Among them, $w_{c}\left(s_{t}\right)=w_{1 c}+\left(w_{2 c}-w_{1 c}\right)\left(s_{t}-1\right)$

$$
w_{f}\left(s_{t}\right)=w_{1 f}+\left(w_{2 f}-w_{1 f}\right)\left(s_{t}-1\right)
$$

Among them, $w_{1 g}, w_{1 f}, w_{2 g}, w_{2 c}, w_{2 f} \geq 0, w_{1 g}+w_{1 c}+w_{1 f}=1, w_{2 g}+w_{2 c}+w_{2 f}=1$ state variable $S 1=1$ or 2.It represent respectively two states of Copula function when it is in high or low state in the source of contagion financial market. In the mix Copula function, correlation parameter doesn't follow the change of fluctuation system. But weight parameter follows the change of fluctuation system. We can easily catch the change of tail correlation in financial market through analysis the change of weight parameter. For example, if the weight $w_{c}\left(s_{t}\right)$ of Clayton function under high fluctuation system $(\mathrm{S} 1=1)$, we can see that tail correlation become strong under high fluctuation system in the financial market.

\section{Conclusions}

As a new statistical studying tool, Copula function has developed greatly in statistical model and financial application. But as a new thing, Copula function can't avoid being challenged by some scholars. Because of Copula function it has excellent statistical property. Concretely speaking, there are some aspects below that we should study deeper. 
1) The goodness of fitting test of Copula function. The goodness of fit for multielement statistic model is always the key point and difficult point.

2) We can use Copula function modifying traditional multielement statistic model. Multielement statistic model was used to base on multielement normal distribution or multielement $t$ distribution hypothesis. This may not fit with some statistic feather that actual financial data providing. Besides, with the increasing dimension of financial asset, the problem of dimension disaster is more and more serious. We can solve this problem by using Copula function.

3) The application of Copula function in financial market in China. This thesis tries to use Copula function to study deep concrete problems in financial market in China. Because the development of domestic financial market is at primary stage, and financial market and products hasn't full development, the application of domestic Copula function has the problems of limited and low level. With the development of financial market and the enhancement of financial risk precision, the application of Copula function will develop great effect.

\section{Acknowledgment}

It is a pleasure to acknowledge the support of the Support and Co-Building Project from Philosophy and Social Science Research Plan in Heilongjiang Province under Grant No 10E007. The project is: Government Performance Evaluation Theory and Application based on Principal-Agent Relations.

It is also a pleasure to acknowledge the support of the Humanities and Social Science Research Fund from Education Department of Heilongjiang Province under Grant No 12522117. The project is: Research on Inflation Governance Countermeasures in the Era of Post-crisis of Finance.

It is also a pleasure to acknowledge the support of the Humanities and Social Science Project from Harbin Normal University for the research under Grant No SYG2009-05. The project is: Mechanisms of Financial Crisis Impact on National Economic Security and Countermeasure Analysis.

\section{References}

[1] Boyer B H, Gibson M S, Loretan M. Pit falls in tests for changes in correlation. Internati onal Finance Discussion Paper No.597.1999

[2] Rodriguez J C. Measuring financial contagion: a copula approach. Working Paper of Europ ean Institute for Statistics, Probability, Operation Research and their Applications. 2003.

[3] Forbes K, Rigobon R. No contagion, only interdependence: measuring stock markets move ments [J]. Journal of Finance, 2002,57(5):2223-2261.

[4] Baig T, Goldfaijn. Financial market contagion in the Asian crisis. Working Paper of IMF Staff.1998

[5] Skintzi, V and A. Refenes. Volatility spillovers and dynamic correlation in European bond markets [J]. Journal of International Financial Markets, Institutions \& Money, 2006.16(1):P.2 3.40 .

[6] Patton, A. J. Modeling asymmetric exchange rate dependence. International Economic Revi ew, 2006. 47(2): P527-556.

[7] Calvo S, Reinhart C .Capital Flows to Latin America: Is There Evidence of Contagion Eff ects? Working Paper.1996.

[8] Longin F, Solnik B. Is the Correlation in International Equity Returns Constant:1960-1990? [J].Journal of International Money and Finance.1995,14:3-26. 